\title{
USO DE DRONES NA ÁREA DE PATOLOGIA DAS CONSTRUÇÕES: ANDAMENTO DA PESQUISA NO BRASIL
}

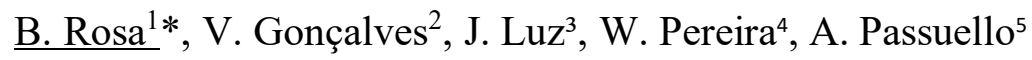 \\ *Autor de Contato: brunarosa94@hotmail.com
}

\footnotetext{
${ }^{1}$ Universidade Federal do Recôncavo da Bahia, Cruz das Almas-BA, Brasil, brunarosa94@hotmail.com

${ }^{2}$ Universidade Federal da Bahia, Salvador-BA, Brasil, vanessaedfgg@gmail.com

${ }^{3}$ Universidade Federal do Recôncavo da Bahia, Cruz das Almas-BA, Brasil, jessica_stephany@hotmail.com

${ }^{4}$ FACTIVA, Valença-BA, Brasil, w.pereira@hotmail.com

${ }^{5}$ Universidade Federal do Recôncavo da Bahia, Cruz das Almas-BA, Brasil, passuello@ufrb.edu.br
}

\begin{abstract}
RESUMO
A aplicação dos drones nas atividades de inspeções das construções é uma abordagem que vem se difundindo em âmbito acadêmico, sendo possível encontrar diversas pesquisas que apresentam o emprego dessa ferramenta na engenharia diagnóstica. Nesse contexto, esta pesquisa visa analisar se existe padronização de procedimentos metodológicos para utilização do drone na identificação de manifestações patológicas. Para isto, utilizou-se um recorte dos anais do Congresso Brasileiro de Patologia (CBPAT) referente aos anos de 2014 a 2020. Observou-se que, no Brasil, existe uma deficiência no que tange a padronização dos procedimentos, bem como a necessidade de mais estudos para cobertura de outras lacunas.
\end{abstract}

Palavras chave: Drone; Engenharia diagnóstica; Inspeções; Manifestações patológicas.

\section{RESUMEN}

La aplicación de drones en las actividades de inspección de la construcción es un enfoque que se ha ido extendiendo en el ámbito académico, y es posible encontrar varias investigaciones que presentan el uso de esta herramienta en la ingeniería de diagnóstico. Esta investigación tiene como objetivo analizar si existe una estandarización de los procedimientos metodológicos para el uso del dron en la identificación de daños. Para ello, utilizamos un recorte de los anales del CBPAT para los años 2014 a 2020. Se observó que, en Brasil, existe una deficiencia en la estandarización de procedimientos, así como la necesidad de más estudios para cubrir otras brechas.

Palabras clave: Drone; Ingeniería de diagnóstico; Inspecciones; daños.

\begin{abstract}
The application of drones in construction inspection activities is an approach that has been spreading in the academic field, and it is possible to find several researches that present the use of this tool in diagnostic engineering. This research aims to analyze if there is a standardization of methodological procedures for the use of the drone in the identification of damages. For this, we used a clipping from the annals of CBPAT for the years 2014 to 2020. It was observed that, in Brazil, there is a deficiency regarding the standardization of procedures, as well as the need for
\end{abstract}


further studies to cover other gaps.

Key words: Drone; Diagnostic engineering; Inspections; Damage.

\section{INTRODUÇÃO}

De acordo a norma de desempenho NBR 15575-1 (ABNT, 2013), as inspeções prediais são caracterizadas como uma importante ferramenta para avaliação das condições gerais de conservação das edificações, pois servem para atestar se os procedimentos de manutenção adotados são insuficientes ou inexistentes, além de fornecer subsídios para orientar planos e programas de manutenção.

A inspeção é o levantamento de informações sobre a edificação (ou estrutura) que permita a avaliação do seu estado de conservação, sendo realizada através de uma vistoria e anamnese. De acordo com a norma NBR 16747 (ABNT, 2020), a inspeção é o processo de avaliação das condições técnicas, de uso, operação, manutenção e funcionalidade de um sistema ou subsistema construtivo, de forma sistêmica e predominantemente sensorial. Convencionalmente, a inspeção é baseada inicialmente na investigação visual, que se destaca como a técnica mais difundida devido ao seu caráter não-destrutivo, simplicidade de execução e instantaneidade dos resultados (Tondelo; Barth, 2019). Entretanto, existem falhas e/ou anomalias que requerem de outras medidas investigativas complementares, a partir da realização de ensaios destrutivos e não destrutivos (Melo Júnior, 2016).

O desenvolvimento de uma inspeção visual pode estar atrelado a certo nível de complexidade, visto que para acessar visualmente a fachada de edifícios e outras estruturas de grande porte, o inspetor necessita realizar um trabalho em altura, alcançando determinadas regiões da estrutura que podem ser de difícil acesso. Em vista disso, a utilização de equipamentos como andaimes, rapel e plataformas se tornam frequentes para o desdobramento da atividade, demandando um tempo relativamente grande para que todo o aparato seja instalado e a vistoria realizada.

Conforme dados divulgados pelo Ministério do Trabalho e Emprego, 40\% dos acidentes de trabalho no Brasil estão relacionados a quedas de funcionários em altura (Agência FIEP, 2019). Contudo, o risco imposto a vida do inspetor e a demora na realização dos serviços de inspeções, fomenta o desenvolvimento de pesquisas que buscam alternativas para o aprimoramento das inspeções. Os veículos aéreos não tripulados (VANTs) fazem parte de um tipo de tecnologia que vem sendo aplicada para facilitar os procedimentos de inspeções.

O VANT é uma aeronave que pode ser pilotada a partir do solo por meio de um comando manual ou automático, sendo capaz de transportar diversos tipos de sensores, responsáveis pelo registro de dados. As câmeras RGB, infravermelhas, termais, multiespectrais e o GPS são exemplos variados de sensores. Além do registro das coordenadas geográficas durante o voo, a existência do GPS garante segurança do próprio equipamento, visto que é responsável pela função Return to home, em que a aeronave retorna para o ponto de partida mesmo que haja perda de contato com o sistema de informação (Agostinho, 2012; Melo, 2016).

Os VANTs são divididos em dois grandes grupos em função do tipo de asa que possui, podendo elas serem fixas ou rotativas. Os de asas fixas são mais indicados para voos longos sobre áreas abertas e de grande extensão. Enquanto os de asas rotativas, também denominados de multirrotores, e popularmente conhecidos por drones, são ideais para atividades que necessitem da execução de manobras complexas em espaços limitados sem perder estabilidade, características requeridas numa atividade de inspeção (Rauber et al., 2018).

A inserção dos drones em inspeções é um tema que vem se difundindo no âmbito acadêmico, sendo possível encontrar diversas pesquisas que abordam o emprego dessa ferramenta 
no levantamento de manifestações patológicas. Dentre esses trabalhos é possível citar o de Eschmann et al. (2012), no qual foi avaliado a utilização de um sistema de micro veículos aéreos do tipo octocóptero (oito hélices) para realização de inspeções e monitoramento de edifícios. $\mathrm{O}$ estudo buscou avaliar se as inúmeras imagens obtidas poderiam ser utilizadas na construção de uma imagem 2D única da estrutura, com a definição adequada para identificar danos e rachaduras em escala milimétrica. De acordo com os autores, a utilização do octocóptero para a inspeção de edifícios se mostrou satisfatória proporcionando uma base de dados primária para esta finalidade. Entretanto, os mesmos autores salientam que, para o modelo de drone utilizado na pesquisa, ainda são necessárias evoluções tecnológicas, especialmente no que diz respeito a estabilização do voo para aquisição das imagens.

Tondelo e Barth (2019) avaliaram em seus estudos os aspectos construtivos e manifestações patológicas de fachadas industriais utilizando um drone modelo Phantom 3. Ao final do trabalho, os autores concluíram que a inspeção realizada com este equipamento se revelou eficiente na identificação das manifestações patológicas, visto que permitiu a obtenção de imagens de qualidade, alcançando locais de difícil acesso em um tempo de execução muito inferior ao procedimento tradicional.

Agostinho (2012) também buscou investigar os benefícios da utilização dessa tecnologia na avaliação de infraestruturas. No seu estudo, Agostinho realizou três inspeções na cidade de Funchal em Portugal, a primeira no Porto do Funchal no qual observou o estado de conservação da estrutura, a segunda, o pilar da Ponte João Gomes e por último o voo no edifício da Universidade da Madeira na Penteada. O autor utilizou sensores RGB e termais que o levaram a obter excelentes resultados com a inspeção, dando condições plenas na observação rápida do real estado de degradação das estruturas, incluindo, inclusive, a visualização de fissuras. $\mathrm{O}$ autor destaca que as vantagens do uso de drones para a funcionalidade estudada estão relacionadas especialmente a obtenção de dados com rapidez, tanto em tempo real quanto após refinamento, com segurança e baixo custo.

Rauber et al. (2018) refletiram sobre os parâmetros que devem ser considerados na escolha de equipamentos para aquisição de imagens em estruturas de obras de artes especiais (OAEs), como as pontes e viadutos. Os autores avaliaram modelos de VANT, sensor, software, controle de voo e gimbal (suporte acoplado ao sensor que viabiliza a rotação em torno dos eixos). Assim, perceberam que com uma boa escolha de equipamentos, as inspeções de pontes e viadutos podem ser realizadas com qualidade. Salientam que, em concomitância com uma adequada interpretação e diagnóstico, imagens captadas por drones podem garantir a identificação de amplos tipos de manifestações patológicas.

Melo Júnior et al. (2018) buscaram explorar em seus estudos o uso de drones combinados a técnica DSM (Dense Stereo Matching), utilizando o software Tyche (2015) e algoritmos computacionais para processamento digital das imagens capturadas e geração de mapa de danos. A partir da utilização da técnica, foi gerada uma nuvem de pontos que possibilitou a retificação das fotografias para projeção ortográfica das fachadas, permitindo uma visualização mais abrangente e precisa dos danos. Os autores também destacam a eficiência destes equipamentos na inspeção de fachadas de edifícios, bem como sua capacidade na identificação de danos em pontes e barragens.

Lima et al. (2020) realizaram estudos com o auxílio de uma aeronave do tipo quadricoptero (drone de quatro hélices) e software de fotogrametria digital Agisoft. Uma edificação com cerca 120,5 metros foi fotografada em torno de 942 vezes e foram identificadas diversas manifestações patológicas, tais como mofo, eflorescência, trincas/fissuras. A principal limitação do estudo destacada pelos autores foi a interrupção do processo devido à baixa duração da bateria, cuja autonomia era de aproximadamente 25 minutos. Porém, os mesmos salientam que as vantagens da técnica a despeito dos métodos tradicionais justificam o uso da aeronave. 
O emprego do drone como ferramenta de inspeção na construção civil ainda é um estudo relativamente novo e não existem normas que formalizem seu uso e estabeleçam procedimentos padronizados para uma inspeção com estes equipamentos. Nesse contexto, a presente pesquisa visa fazer uma revisão bibliográfica aprofundada, abordando os trabalhos acadêmicos na área de patologia das construções que focaram no uso drones como ferramenta para a coleta de dados remota. $\mathrm{O}$ trabalho busca contribuir na análise dos procedimentos adotados para o levantamento de manifestações patológicas, identificando se os procedimentos metodológicos seguiram algum tipo de padronização, bem como levantar as principais vantagens e limitações encontradas pelos autores. $\mathrm{O}$ artigo tem como recorte os trabalhos publicados no Congresso Brasileiro de Patologia (CBPAT).

\section{PROCEDIMENTOS}

O estudo em questão é classificado como exploratório e descritivo, com abordagem quantitativa e qualitativa. A pesquisa visa levantar se existe padronização metodológica nos procedimentos dos pesquisadores dos artigos do Congresso Brasileiro de Patologia, bem como vantagens e dificuldades encontradas a partir do uso de drone em inspeções voltadas para identificação de manifestações patológicas. Para isso, foi utilizado como metodologia a análise de conteúdo proposto por Bardin (1977), no qual está embasada em três fases distintas:

FASE 1 - Pré-análise: Esta fase inicial está relacionada a organização dos dados de interesse da pesquisa a partir de uma busca através de palavras-chaves selecionadas para este estudo, sendo elas: VANT; Drone; UAV. Está última sendo a sigla em inglês de VANT. A seleção definitiva ocorreu após leitura dos resumos. Os artigos selecionados para o estudo foram correspondentes aos anos de 2014 e 2020, cujas edições ocorreram a cada dois anos. Os anais dos anos 2014, 2016 e 2018 foram disponibilizados pela organização do evento, enquanto os anais de 2020 foram acessados eletronicamente, visto que as autoras participaram do respectivo evento.

FASE 2 - Exploração do material: A partir de uma leitura mais aprofundada, esta fase busca categorizar os conteúdos através de critérios de interesse na pesquisa, denominados neste estudo de índices paramétricos. Os índices categorizados foram: Ano, título, drone/sensor, objeto de estudo, objetivo de pesquisa, metodologia, vantagens e limitações da técnica. As informações foram planilhadas através do software MS-Excel.

FASE 3 - Tratamento e análise dos dados: Por fim, a última fase foi voltada ao tratamento e análise dos dados. Nesta fase os dados foram quantificados e sistematizados em quadros sínteses, tabelas e gráficos, de forma a fazer uma análise quantitativa e qualitativa da implementação dos drones como ferramenta de auxílio às inspeções na área de patologia das construções. Os dados foram divididos em três blocos de análises, conforme apresentado na Figura 1. No BLOCO 1 foram introduzidos os artigos contemplados no estudo através dos índices paramétricos: ano de publicação; título; modelo de drone e; objeto de estudo. Esta divisão permitiu mensurar o quantitativo do número de artigos que contemplassem os critérios de pesquisa, bem como compreender, a partir dos títulos, se os autores associam novas tecnologias nas inspeções, pelo fato de usarem palavras como inovação/modernização. No BLOCO 2 foi realizada uma síntese dos índices paramétricos relacionados ao objetivo da pesquisa e metodologia. Em relação ao objetivo de pesquisa, buscou-se avaliar quais artigos eram voltados a identificar manifestações patológicas e quais tipos de estruturas foram alvo das inspeções. Para a análise da metodologia primeiro observou-se se a pesquisa era de cunho experimental ou de revisão bibliográfica. Para os artigos que desenvolveram programas experimentais, analisou o método/procedimento de voo, bem como da captura das imagens. Em procedimento de voo buscou-se identificar as informações relativas as condições meteorológicas, velocidade de voo, local de pouso/decolagem e observação da região a ser mapeada. Em relação à captura de imagem observou-se dados sobre a técnica de coleta de 
imagens, sobreposição, distância do objeto de estudo e tratamento dos dados. Também buscou-se classificar os artigos em relação ao desenho experimental no que se refere aos métodos de voo e obtenção de imagens. Os artigos que possuíam informações sobre todos os critérios metodológicos observados para método de voo e de captura das imagens foram enquadrados como PROGRAMA EXPERIMENTAL COMPLETO. Para aqueles que não apresentaram todos os critérios enquadrou-se como PROGRAMA EXPERIMENTAL INCOMPLETO e, ainda, para aqueles que não apresentaram nenhum tipo de informação classificou-se como NÃO MENCIONADO. Por fim, o BLOCO 3 focou nos índices paramétricos vantagens e barreiras. Nesta etapa da análise observou-se se os artigos especificavam vantagens em relação aos aspectos de funcionalidade, segurança e economia dos equipamentos, resultados satisfatórios quanto à identificação de danos, bem como se apontavam se as limitações encontradas ao longo do estudo poderiam, e de que forma, ter sido solucionadas.

Figura 1: Fluxograma do método de análise dos dados levantados na pesquisa

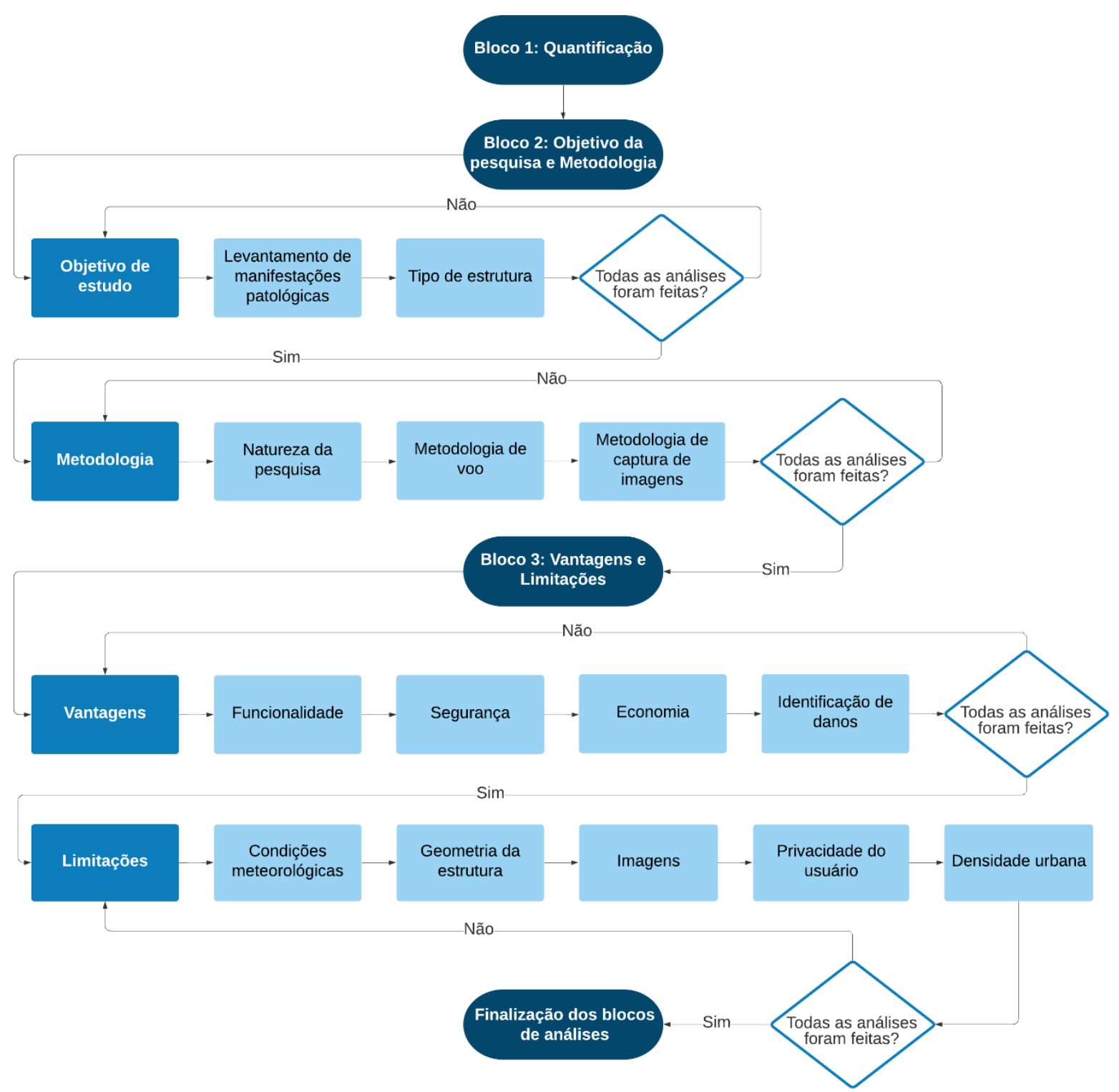

\section{RESULTADOS}


A Tabela 1 apresenta os resultados obtidos a partir da pré-análise dos artigos dos Anais do CBPAT (FASE 1). A pesquisa identificou um total de 10 artigos que incluíram drone como ferramenta de auxílio para a realização de inspeções no levantamento de manifestações patológicas. Foi possível perceber que todos os trabalhos identificados faziam parte das duas últimas edições do evento (2018 e 2020), não sendo identificado trabalhos nas duas primeiras edições (2014 e 2016).

Tabela 1: Quantitativo dos artigos publicados nas edições do Congresso Brasileiro de Patologia das Construções - CBPAT

\begin{tabular}{|c|c|c|}
\hline Ano & Totais & Artigos com drone \\
\hline 2014 & 114 & 0 \\
\hline 2016 & 444 & 0 \\
\hline 2018 & 172 & 1 \\
\hline 2020 & 368 & 9 \\
\hline TOTAL & 1098 & 10 \\
\hline
\end{tabular}

A partir da Tabela 1 foi possível constatar que, mesmo com muitos artigos aceitos nas edições ocorridas nos anos de 2014 e 2016 (total de 558), nenhum deles incorporou drones nos estudos realizados. Seria possível inferir que o emprego das aeronaves, ainda, não era difundido como uma viabilidade de instrumento de estudo. No entanto, conforme Neto (2015), esse desafio pela inserção do drone pode ser justificado pela descrença do mercado nos produtos gerados pelos drones, especialmente o setor de geotecnologia, uma vez que não haviam softwares específicos para o processamento de dados provenientes dos drones. Ainda segundo o autor, o surgimento de novos algoritmos de processamento, e, consequentemente, o processamento das imagens dos drones, proporcionou a validação e amadurecimento da ferramenta no mercado a partir do ano de 2014. Em contrapartida, a partir de 2018 identifica-se a inserção de drones na pesquisa, sendo 1 (um) na edição de 2018 e 9 (nove) na edição em 2020. Este último foi o ano da última edição que aconteceu de forma remota em função da Pandemia do COVID-19. Considerando que o aumento da oferta de drones no mercado, inclusive com valores acessíveis ao consumidor comum, é bastante recente e compreensível que o número de trabalhos do CBPAT foi nulo nas duas primeiras edições do evento no Brasil. A adesão no uso de drones ainda estava sendo consolidada no cenário internacional e inclusive, ainda muito restrita ao setor cartográfico. Muito recentemente é que pesquisas para novos segmentos foram ampliadas, como no próprio setor da construção civil.

O Quadro 1 apresenta os índices paramétricos (ano, autor, título, objeto de estudo, drone/câmera) estabelecidos para o BLOCO 1 da FASE 3. Analisando o parâmetro título em conjunto com objeto de estudo é possível perceber a frequência de palavras que indicam que o artigo está associado ao uso de novas tecnologias em inspeções (INOVAÇÃO E MODERNIZAÇÃO), bem como os maiores destaques dos estudos voltados aos elementos de fachadas. 
Quadro 1: Parâmetros de apresentação dos artigos do CBPAT

\begin{tabular}{|c|c|c|c|c|c|}
\hline $\mathbf{N}^{\circ}$ & Ano & Autor & Título & $\begin{array}{l}\text { Objeto de } \\
\text { estudo }\end{array}$ & Drone/ Câmera \\
\hline 1 & 2018 & \begin{tabular}{|l} 
Rios, R., \\
Blumensche \\
in,R., \\
Zanoni,V.
\end{tabular} & $\begin{array}{l}\text { Parâmetros para escolha de ensaios } \\
\text { tradicionais e inovadores } \\
\text { para inspeção preliminar de fachadas }\end{array}$ & Fachada & - \\
\hline 2 & 2020 & $\begin{array}{l}\text { Moura JR., } \\
\text { J. M. et al }\end{array}$ & $\begin{array}{l}\text { Estudo exploratório de inspeção de } \\
\text { manifestações patológicas de } \\
\text { fachadas utilizando veículo aéreo } \\
\text { não tripulado (VANT) }\end{array}$ & Fachada & $\begin{array}{c}\text { DJI Phantom } 4 \text { PRO } \\
\text { Plus/ RGB }\end{array}$ \\
\hline 3 & 2020 & $\begin{array}{l}\text { Ruiz, R. D. } \\
\text { B. et al }\end{array}$ & $\begin{array}{c}\text { Inovação na inspeção de fachadas } \\
\text { com veículos aéreos não tripulados } \\
\text { (VANT) }\end{array}$ & Fachada & $\begin{array}{c}\text { DJI Phantom } 4 \text { Pro V } \\
\text { 2.0/ RGB }\end{array}$ \\
\hline 4 & 2020 & $\begin{array}{l}\text { França, G. et } \\
\text { al }\end{array}$ & $\begin{array}{c}\text { Utilização de drone na avaliação de } \\
\text { patologias em fachadas de } \\
\text { edificações }\end{array}$ & Fachada & $\begin{array}{l}\text { DJI Phanton } 4 \text { Pro/ } \\
\text { RGB }\end{array}$ \\
\hline 5 & 2020 & $\begin{array}{l}\text { Silva, R. C. } \\
\text { et al }\end{array}$ & $\begin{array}{l}\text { Modernização da inspeção e } \\
\text { avaliação de estruturas: as } \\
\text { contribuições de VANTs e robôs na } \\
\text { área de patologia das construções }\end{array}$ & $\begin{array}{l}\text { Ponte } \\
\text { Estrada }\end{array}$ & -------------- \\
\hline 6 & 2020 & $\begin{array}{l}\text { Silva, W. et } \\
\text { al }\end{array}$ & $\begin{array}{l}\text { Inovação tecnológica na inspeção de } \\
\text { manifestações patológicas de } \\
\text { fachadas utilizando câmera } \\
\text { termográfica integrada ao veículo } \\
\text { aéreo não tripulado (VANT): } \\
\text { revisão bibliográfica }\end{array}$ & Fachada & Câmera termográfica \\
\hline 7 & 2020 & $\begin{array}{l}\text { Araújo, W. } \\
\text { et al }\end{array}$ & $\begin{array}{l}\text { Avaliação de manifestações } \\
\text { patológicas com uso de drone }\end{array}$ & Reservatório & $\begin{array}{l}\text { DJI Phantom } 3 \\
\text { Profissional }\end{array}$ \\
\hline 8 & 2020 & $\begin{array}{l}\text { Sollero, M. } \\
\text { B .S. et al }\end{array}$ & $\begin{array}{l}\text { Uma revisão das últimas inovações } \\
\text { em inspeções de estruturas }\end{array}$ & $\begin{array}{c}\text { Ponte } \\
\text { Cobertura }\end{array}$ & --- \\
\hline 9 & 2020 & $\begin{array}{l}\text { Rosenberg, } \\
\text { A.C et al }\end{array}$ & $\begin{array}{l}\text { Estudo de ocorrências patológicas } \\
\text { em pontes com a utilização de } \\
\text { veículos aéreos não tripulados }\end{array}$ & Ponte & --- \\
\hline 10 & 2020 & $\begin{array}{l}\text { Solanho, B } \\
\text { P. et al }\end{array}$ & $\begin{array}{l}\text { Verificação da eficiência da } \\
\text { inspeção virtual de manifestações } \\
\text { patológicas em fachadas de edifícios } \\
\text { com diferentes revestimentos }\end{array}$ & Fachada & $\begin{array}{l}\text { DJI Phantom } 3 \\
\text { Advanced }\end{array}$ \\
\hline
\end{tabular}

O Gráfico 1 apresenta o percentual de vezes que palavras inovação e modernização aparecem no título e o Gráfico 2 os tipos de objetos de inspeção que fazem parte dos trabalhos. Segundo o Gráfico 1, a frequência da palavra "Inovação" e "Modernização" está presente nos títulos dos trabalhos em cerca de 5 (cinco) artigos. Já o Gráfico 2, demonstra que das 10 (dez) pesquisas que utilizaram drones na área de estruturas tem-se 1 (um) trabalho em pontes, 1 (um) em 
reservatórios, 2 (dois) mistos em estradas e coberturas e 6 (seis) trabalhos que foram voltados para estudos de fachadas. Essa constância permite observar sobre o crescimento do interesse na aplicação de tecnologias existentes, como o drone, em inspeções. Esse interesse pode inferir sobre o intuito na modernização da técnica, especialmente no diagnóstico em fachadas, que promete resultados com maior velocidade, segurança e economia para investigação de manifestações patológicas.

Gráfico 1: Frequência da palavra modernização/ inovação

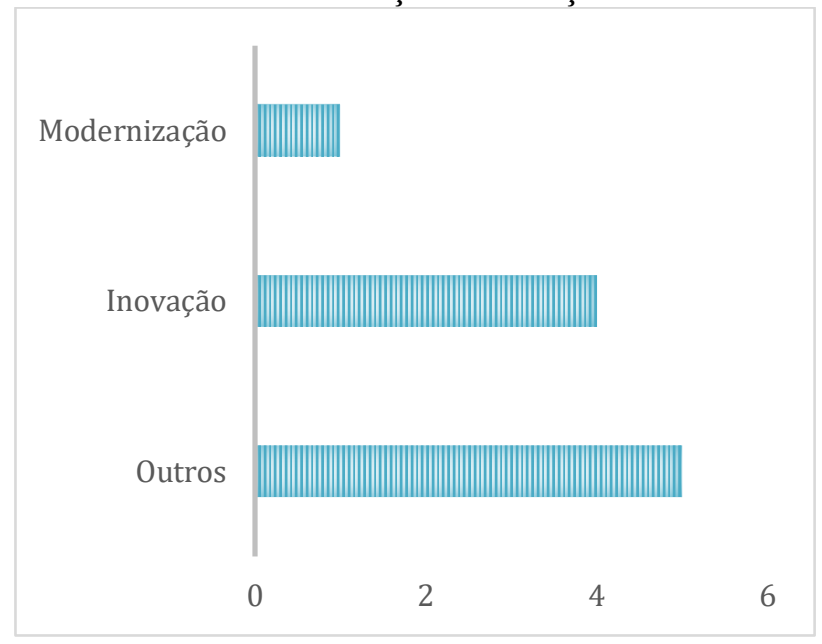

Gráfico 2: Objeto de estudo da inspeção

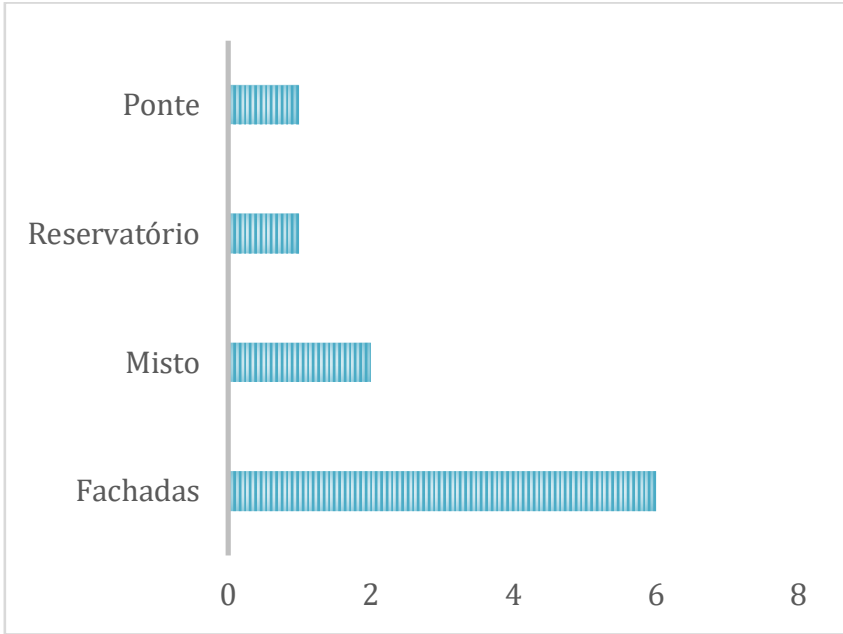

Ainda conforme o Quadro 1, em relação aos tipos de VANTs e sensores, pode-se perceber a maior frequência de uso do modelo Phantom, da DJI, especialmente o modelo DJI Phantom 4 Pro que foi o mais utilizado. Sabe-se que esse produto possui uma oferta bastante expressiva no mercado, com preços variados. A facilidade de manuseio do equipamento, o preço acessível, além de confiabilidade e precisão na coleta de dados, justificam a escolha deste modelo por diversos autores (Irrizarry; Costa, 2016; Melo Jr, 2016; Álvares, 2016; Hung et al, 2018). Ademais, podese observar que o custo acessível, em paralelo com os demais parâmetros apresentados, pode ampliar ainda mais o número de estudos com o uso desta tecnologia. Com o avanço da pesquisa nesta área tem-se a possibilidade de se estabelecer estratégias normativas que permitam aumentar a frequência de inspeções rotineiras em estruturas, garantindo um melhor planejamento de manutenções. Além disso, percebe-se no Quadro 1 que a maioria dos estudos são realizados com sensores do tipo RGB. Este tipo de sensor nada mais é do que câmeras comuns (fotografia e vídeo), que proporcionam uma visualização similar a visão humana. Também são sensores de custo bastante acessível.

O Quadro 2 apresenta a síntese dos índices paramétricos (objetivo e natureza da pesquisa, método de realização do voo e obtenção das imagens) do BLOCO 2 relativos à FASE 3 deste estudo. Neste quadro são elencados os objetivos dos artigos e o método de pesquisa adotado.

Quadro 2: Síntese do objeto de estudo e metodologia dos artigos do CBPAT

\begin{tabular}{|c|c|c|c|c|}
\hline $\mathbf{N}^{\circ}$ & Objetivo da pesquisa & $\begin{array}{c}\text { Natureza } \\
\text { da } \\
\text { pesquisa }\end{array}$ & $\begin{array}{c}\text { Método para realização } \\
\text { do voo }\end{array}$ & $\begin{array}{c}\text { Método para obtenção } \\
\text { das imagens }\end{array}$ \\
\hline 1 & $\begin{array}{c}\text { Discutir e propor } \\
\text { diretrizes para o } \\
\text { processo de seleção dos } \\
\text { ensaios de fachadas, } \\
\text { tradicionais e inovadores } \\
\text { na construção brasileira. }\end{array}$ & $\begin{array}{c}\text { Exploratória } \\
\text { teórica }\end{array}$ & Não se aplica & Não se aplica \\
\hline
\end{tabular}




\begin{tabular}{|c|c|c|c|c|}
\hline 2 & \begin{tabular}{|} 
Caracterizar o panorama \\
atual das empresas de \\
drone na Região \\
Metropolitana de Recife. \\
Bem como realizar \\
inspeção de fachada, \\
visando identificar \\
patologias em fachadas.
\end{tabular} & $\begin{array}{c}\text { Exploratória } \\
\text { de campo }\end{array}$ & $\begin{array}{l}\text { Análise de condições } \\
\text { meteorológicas: Sim; } \\
\text { Velocidade de voo: Sim; } \\
\text { Escolha de decolagem/pouso: } \\
\text { Sim; } \\
\text { Análise das dificuldades da } \\
\text { região a ser mapeada (área } \\
\text { urbana habitada, fluxo } \\
\text { veicular, edificações } \\
\text { circundantes): Sim; }\end{array}$ & $\begin{array}{c}\text { Técnica de coleta de } \\
\text { imagens: Sim; } \\
\text { Técnica de Sobreposição: } \\
\text { Sim; } \\
\text { Técnica de Distância: Sim; } \\
\text { Análise de dados: } \\
\text { Fotogrametria ( Software } \\
\text { Agisoft Photoscan - } \\
\text { Modelagem 3D) }\end{array}$ \\
\hline 3 & $\begin{array}{c}\text { Estudo experimental do } \\
\text { uso de VANT como } \\
\text { ferramenta visual para } \\
\text { inspeção de } \\
\text { manifestações } \\
\text { patológicas em fachadas. }\end{array}$ & $\begin{array}{c}\text { Exploratória } \\
\text { de campo }\end{array}$ & $\begin{array}{l}\text { Análise de condições } \\
\text { meteorológicas: Não; } \\
\text { Velocidade de voo: Sim; } \\
\text { Escolha de decolagem/pouso: } \\
\text { Sim; } \\
\text { Análise das dificuldades da } \\
\text { região a ser mapeada (área } \\
\text { urbana habitada, fluxo } \\
\text { veicular, edificações } \\
\text { circundantes): Sim; }\end{array}$ & $\begin{array}{c}\text { Técnica de coleta de } \\
\text { imagens: Sim; Técnica de } \\
\text { Sobreposição: Sim; } \\
\text { Técnica de Distância: Sim; } \\
\text { Análise de dados: } \\
\text { Fotogrametria Software } \\
\text { Agisoft Photoscan - } \\
\text { Modelagem 3D), } \\
\text { Orthomosaico. }\end{array}$ \\
\hline 4 & $\begin{array}{c}\text { Avaliar as manifestações } \\
\text { patológicas em fachadas } \\
\text { de três edificações na } \\
\text { cidade de Natal/RN e } \\
\text { região metropolitana. }\end{array}$ & $\begin{array}{c}\text { Exploratória } \\
\text { de campo }\end{array}$ & $\begin{array}{c}\text { Análise de condições } \\
\text { meteorológicas: Não; } \\
\text { Velocidade de voo: Não } \\
\text { mencionou; } \\
\text { Escolha de decolagem/pouso: } \\
\text { Sim; } \\
\text { Análise das dificuldades da } \\
\text { região a ser mapeada (área } \\
\text { urbana habitada, fluxo } \\
\text { veicular, edificações } \\
\text { circundantes): Sim; }\end{array}$ & $\begin{array}{c}\text { Técnica de coleta de } \\
\text { imagens: Sim Técnica de } \\
\text { Sobreposição: Sim; } \\
\text { Técnica de Distância: Não } \\
\text { mencionou; } \\
\text { Análise de dados: } \\
\text { Fotogrametria (Software } \\
\text { Agisoft Photoscan - } \\
\text { Modelagem 3D), } \\
\text { Orthomosaico. }\end{array}$ \\
\hline 5 & $\begin{array}{l}\text { Mostrar as } \\
\text { potencialidades do } \\
\text { emprego de VANTs e } \\
\text { robôs na construção } \\
\text { civil, por meio de uma } \\
\text { revisão bibliográfica. }\end{array}$ & $\begin{array}{c}\text { Revisão } \\
\text { Bibliográfica }\end{array}$ & Não se aplica & Não se aplica \\
\hline 6 & $\begin{array}{c}\text { Apresentar pesquisa } \\
\text { relativa ao emprego de } \\
\text { câmera termográfica } \\
\text { integrada ao VANT nos } \\
\text { processos de inspeção de } \\
\text { fachadas. }\end{array}$ & $\begin{array}{c}\text { Revisão } \\
\text { Bibliográfica }\end{array}$ & Não se aplica & Não se aplica \\
\hline 7 & \begin{tabular}{|c|} 
Realizar um \\
levantamento de \\
manifestação patológica \\
do reservatório elevado \\
na cidade de Prata/PB. \\
\end{tabular} & $\begin{array}{c}\text { Exploratória } \\
\text { de campo }\end{array}$ & Não mencionado & Não mencionado \\
\hline 8 & $\begin{array}{c}\text { Apresentar um } \\
\text { panorama das inovações } \\
\text { atualmente empregadas } \\
\text { na inspeção de estruturas } \\
\text { em diversos países. } \\
\end{array}$ & $\begin{array}{c}\text { Revisão } \\
\text { Bibliográfica }\end{array}$ & Não se aplica & Não se aplica \\
\hline
\end{tabular}




\begin{tabular}{|c|c|c|c|c|}
\hline 9 & $\begin{array}{c}\text { Apresentar o estudo da } \\
\text { aplicação de VANT na } \\
\text { realização de inspeção } \\
\text { da Ponte do Rio Jacú } \\
\text { Braço Norte, bem como } \\
\text { vantagens e limitações, } \\
\text { em relação a inspeção } \\
\text { tradicional. }\end{array}$ & $\begin{array}{l}\text { Exploratória } \\
\text { de campo }\end{array}$ & \begin{tabular}{|c|} 
Análise de condições \\
meteorológicas: Não; \\
Velocidade de voo: Não \\
mencionou; \\
Escolha de decolagem/pouso: \\
Não mencionou; \\
Análise das dificuldades da \\
região a ser mapeada (área \\
urbana habitada, fluxo \\
veicular, edificações \\
circundantes): Sim; \\
\end{tabular} & $\begin{array}{l}\text { Técnica de coleta de } \\
\text { imagens: Sim; } \\
\text { Técnica de Sobreposição: } \\
\text { Não mencionou; } \\
\text { Técnica de Distância: Não } \\
\text { mencionou; } \\
\text { Análise de dados: } \\
\text { Fotogrametria. }\end{array}$ \\
\hline 10 & $\begin{array}{c}\text { Comparar a eficiência da } \\
\text { inspeção virtual com a } \\
\text { inspeção física em } \\
\text { fachadas com diferentes } \\
\text { revestimentos e também } \\
\text { a viabilidade econômica. }\end{array}$ & $\begin{array}{l}\text { Exploratória } \\
\text { de campo }\end{array}$ & \begin{tabular}{|c|} 
Análise de condições \\
meteorológicas: Não; \\
Velocidade de voo: Sim; \\
Escolha de decolagem/pouso: \\
Não mencionou; \\
Análise das dificuldades da \\
região a ser mapeada (área \\
urbana habitada, fluxo \\
veicular, edificações \\
circundantes): Sim; \\
\end{tabular} & $\begin{array}{l}\text { Técnica de coleta de } \\
\text { imagens: Sim; Técnica de } \\
\text { Sobreposição: Não } \\
\text { mencionou; } \\
\text { Técnica de Distância: Sim; } \\
\text { Análise de dados: } \\
\text { Aproximação de imagens } \\
\text { com Movie Maker. }\end{array}$ \\
\hline
\end{tabular}

Ao observar os objetivos principais de cada um dos artigos, foi possível verificar que os estudos do CBPAT focaram em pesquisas voltadas à identificação de manifestações patológicas de estruturas, especialmente em fachadas, como visto anteriormente. Nesse contexto, denota-se maiores interesses em fachadas, talvez, na tentativa de incluir o drone como ferramenta visual para o crescimento da realização de etapas rotineiras, visto que a fachada é responsável pela passagem do meio externo para o meio interno (Costa, 2014), além de sua ampla complexidade (altura, tamanho, dificuldade de acesso e condição de exposição) (Moura Jr., 2020). Deste modo, a aeronave se mostra, segundo estudos, uma tecnologia segura, econômica e eficaz para fins de inspeção visando a identificação de fissura, bolor, eflorescência e outras anomalias patológicas.

Observando a natureza das pesquisas nota-se que 6 (seis) são pesquisas práticas, ou seja, que incluíram atividades de campo, e 4 (quatro) teóricas. Dentre aquelas práticas foi realizado um quantitativo em relação aos procedimentos de voo e de captura de imagens como é possível observar na Tabela 2.

Tabela 2: Classificação segundo o desenho experimental.

\begin{tabular}{|c|c|c|c|c|c|}
\hline \multicolumn{7}{|c|}{ Metodologia experimental } \\
\hline \multicolumn{2}{|c|}{ Voo } & \multicolumn{3}{c|}{ Captura de Imagens } \\
\hline Completa & Incompleta & $\begin{array}{c}\text { Não } \\
\text { mencionada }\end{array}$ & Completa & Incompleta & $\begin{array}{c}\text { Não } \\
\text { mencionada }\end{array}$ \\
\hline 1 & 4 & 1 & 2 & 3 & 1 \\
\hline
\end{tabular}

Com base na Tabela 2, nota-se que os procedimentos de voo possuem 1 (um) trabalho com metodologia completa, 4 (quatro) incompletas e 1 (um) trabalho não informou como foi realizado o procedimento de inspeção. Por outro lado, nos procedimentos para captura de imagem 2 (dois) artigos apresentaram planejamento de captura de imagens completos, 3 (incompletos) incompletos e 1 (um) não informou. Os achados evidenciaram que existe uma fragilidade nos padrões relacionados ao planejamento de voo e protocolo de captura de imagem dos artigos envolvidos, bem como a deficiência na compreensão para o uso adequado de drones. Vale salientar que, para 
garantir a qualidade da inspeção, faz-se necessário um planejamento específico e qualificado, com profissionais habilitados, para alcançar resultados satisfatórios na investigação das anomalias patológicas.

O BLOCO 3 relativos à FASE 3, representado pelo Quadro 3, expõe uma síntese dos indicadores pertencentes aos parâmetros de vantagens e limitações encontrados nos resultados dos artigos.

Quadro 3: Síntese de vantagens e barreiras dos artigos do CBPAT

\begin{tabular}{|c|c|c|c|}
\hline $\mathbf{N}^{\circ}$ & Autor & Vantagens & Limitações \\
\hline 1 & $\begin{array}{c}\text { Rios,R., } \\
\text { Blumenschein,R., } \\
\text { Zanoni,V. (2018) } \\
\end{array}$ & $\begin{array}{c}\text { Coleta mais precisa; identificação de } \\
\text { anomalias ocultas - infiltração, } \\
\text { desplacamento. }\end{array}$ & $\begin{array}{c}\text { Afetar a segurança e privacidade do } \\
\text { usuário; }\end{array}$ \\
\hline 2 & $\begin{array}{l}\text { Moura JR., J. M. et } \\
\text { al (2020) }\end{array}$ & $\begin{array}{l}\text { Possibilita identificar manifestações } \\
\text { patológicas em fachadas com uso de } \\
\text { drones; agilidade; menor custo para } \\
\text { locação de equipamento; inspeção } \\
\text { segura. }\end{array}$ & $\begin{array}{l}\text { Utilizar outras ferramentas como } \\
\text { câmera termográfica para infiltrações; } \\
\text { falha no planejamento do voo e falta de } \\
\text { mais imagens; presença de ventos fortes } \\
\text { e luminosidade distinta. }\end{array}$ \\
\hline 3 & $\begin{array}{l}\text { Ruiz, R. D. B. et al } \\
(2020)\end{array}$ & $\begin{array}{l}\text { Reduzir tempo, custos e gerar dados } \\
\text { de forma eficiente. }\end{array}$ & $\begin{array}{l}\text { Características geométricas da } \\
\text { edificação; área urbana densamente } \\
\text { habitada; pontos de decolagem } \\
\text { limitado; ruas com fluxo veicular; } \\
\text { presença de ventos. }\end{array}$ \\
\hline 4 & $\begin{array}{l}\text { França, G. et al } \\
\qquad(2020)\end{array}$ & $\begin{array}{c}\text { Diagnóstico acelerado da análise de } \\
\text { danos, elaboração de procedimento } \\
\text { assertivo para recuperação da } \\
\text { edificação. }\end{array}$ & - \\
\hline 5 & $\begin{array}{l}\text { Silva, R. C. et al } \\
\text { (2020) }\end{array}$ & Mais acessível e menos oneroso & -------- \\
\hline 6 & $\begin{array}{l}\text { Silva, W. et al } \\
\quad(2020)\end{array}$ & $\begin{array}{l}\text { Redução de riscos operacionais; } \\
\text { redução de tempo e custo de } \\
\text { inspeção; maior confiabilidade; } \\
\text { tecnologia não destrutiva. }\end{array}$ & $\begin{array}{l}\text { Ventos acima de } 7 \mathrm{~m} / \mathrm{s} \text { intervém na } \\
\text { qualidade de medições com termografia } \\
\text { infravermelha induzindo ao erro de } \\
\text { análise; fachadas vizinhas espelhadas; } \\
\text { espessura e profundidade da } \\
\text { manifestação patológica. }\end{array}$ \\
\hline 7 & $\begin{array}{l}\text { Araújo,W. et al } \\
\qquad(2020)\end{array}$ & $\begin{array}{l}\text { Eficaz, rápido e preciso no } \\
\text { monitoramento da inspeção. }\end{array}$ & \\
\hline 8 & $\begin{array}{l}\text { Sollero, M. B .S. et } \\
\text { al (2020) }\end{array}$ & $\begin{array}{l}\text { Coletas de dados com mais } \\
\text { segurança e velocidade. }\end{array}$ & \\
\hline 9 & $\begin{array}{c}\text { Rosenberg, A.C et } \\
\text { al }(2020)\end{array}$ & $\begin{array}{l}\text { Inspeção sem a interrupção de } \\
\text { tráfego; redução no número de } \\
\text { profissionais. }\end{array}$ & $\begin{array}{l}\text { Fortes rajadas de vento em região } \\
\text { montanhosa impossibilita a } \\
\text { estabilização de drones }\end{array}$ \\
\hline 10 & $\begin{array}{c}\text { Solanho, B P. et al } \\
(2020)\end{array}$ & $\begin{array}{l}\text { Rapidez na inspeção; menor custo } \\
\text { de aluguel de equipamentos } \\
\text { comparando às horas trabalhadas. }\end{array}$ & $\begin{array}{c}\text { Rajadas de vento; limitação de ângulo } \\
\text { de inclinação da câmera do } \\
\text { equipamento. }\end{array}$ \\
\hline
\end{tabular}


Observando o Quadro 3 é possível perceber que os autores apontaram nos resultados diversas vantagens na utilização de drones nos trabalhos. Dentre as vantagens analisou se as mesmas atendiam aos aspectos de funcionalidade, segurança e economia dos equipamentos, bem como identificação das manifestações patológicas como pode-se ver no Quadro 4.

Quadro 4: Especificação das vantagens em relação aos parâmetros

\begin{tabular}{|c|c|c|}
\hline Atende aos parâmetros ? & Sim & Não \\
\hline $\begin{array}{c}\text { Funcionalidade (precisão, agilidade, fluxo de tráfego sem } \\
\text { interrupção) }\end{array}$ & $\mathrm{x}$ & \\
\hline $\begin{array}{c}\text { Segurança (redução de riscos operacionais) } \\
\text { equipamentos) }\end{array}$ & $\mathrm{x}$ & \\
\hline $\begin{array}{c}\text { Economia (redução de custos, profissionais e aluguel de } \\
\text { Identificação de manifestações patológicas (visíveis- bolor, } \\
\text { eflorescência, fissura; ocultas- infiltração e falha de vedação) }\end{array}$ & $\mathrm{x}$ & \\
\hline
\end{tabular}

Conforme o Quadro 4, nota-se que a utilização de drone nas pesquisas prometem amplas vantagens potenciais de funcionalidade, segurança, economia e demonstra resultados bastante significativos relacionados a identificação de manifestações patológicas visíveis e ocultas. Estudos como o de Rosenberg et al. (2020), demonstram, que o uso de drone em inspeção de pontes descarta a interrupção de tráfego e auxilia de forma não destrutiva para identificação das anomalias. Além disso de acordo com Sollero et al. (2020), há um menor custo de aplicação dessa metodologia quando comparado ao método tradicional. Na identificação de danos ocultos essa tecnologia quando usada em paralelo a outras ferramentas, como a câmera termográfica e software Agisoft Photoscan, permite identificar danos ocultos a olho nu, bem como, tornam-se capazes de medir espessura e comprimento de fissuras. Dessa forma os resultados proporcionam dados mais rebuscados acelerando o diagnóstico para uma tomada de decisão mais assertiva na resolução do problema e viabiliza o produto final para a formulação de um mapa de danos com detalhes precisos e de qualidade visual. Porém, vale salientar que a inclusão dessa ferramenta na inspeção, não excluí a presença de um profissional especialista da engenharia diagnóstica para identificação de anomalias patológicas do objeto a ser estudado, assim como, o piloto da aeronave não tripulada deve ser capacitado para atividade específica e possuir licença para pilotar, caso contrário o drone perderá a sua finalidade de garantir qualidade e segurança. Esses dilemas, capacitação e licença, expostos, fazem parte da pesquisa número 2 , nos quais trazem que somente $33 \%$ das empresas que trabalham com drones possuem pilotos capacitados, o que pode provocar uma grande barreira por contratantes, uma vez que, a busca por soluções preventivas para as medidas aplicadas a determinada manifestação patológica é influenciada por uma inspeção adequada e uma leitura de dados por especialista na área.

Retomando as discussões do Quadro 3, os artigos demonstram algumas limitações que serão discutidas no Quadro 5 analisando se as mesmas podem ser solucionadas.

Quadro 5: Limitações e respectivas soluções dos autores

\begin{tabular}{|c|c|c|}
\hline Limitações & Caracterização & Solução dos autores \\
\hline $\begin{array}{c}\text { Condições } \\
\text { meteorológicas }\end{array}$ & $\begin{array}{c}\text { Vento forte, luminosidade } \\
\text { distinta, chuva. }\end{array}$ & Planejamento de voo \\
\hline Geometria da estrutura & $\begin{array}{c}\text { Arquitetura irregular, } \\
\text { edificação alta. }\end{array}$ & $\begin{array}{c}\text { Planejamento de voo com estudo } \\
\text { de pontos de decolagem/pouso. }\end{array}$ \\
\hline
\end{tabular}




\begin{tabular}{|c|c|c|}
\hline Imagens & $\begin{array}{c}\text { Carência de imagens para } \\
\text { sobreposição. }\end{array}$ & $\begin{array}{c}\text { Protocolo de procedimento } \\
\text { experimental para captura de } \\
\text { imagens. }\end{array}$ \\
\hline Privacidade do usuário & $\begin{array}{c}\text { Privacidade dos usuários } \\
\text { circundantes. }\end{array}$ & $\begin{array}{c}\text { Escolha de horário comercial e } \\
\text { avisos antecipados. }\end{array}$ \\
\hline Densidade urbana & $\begin{array}{c}\text { Pontos de decolagem/pouso } \\
\text { limitado, fluxo veicular. }\end{array}$ & $\begin{array}{c}\text { Escolha de horário de menor fluxo } \\
\text { veicular. }\end{array}$ \\
\hline
\end{tabular}

De acordo com o Quadro 5, nota-se que as barreiras mais apresentadas podem ser solucionadas. Sob o ponto de vista dos estudos que incluíram condições meteorológicas, chuva e vento, como barreiras, autores como Moura Jr et al., Ruiz et al., Rosenberg et al. e Sollero et al. (2020), afirmaram que embora houve dificuldade para estabilizar a ferramenta, a qualidade da foto não foi alterada, e a escolha da data de inspeção deve estar em acordo com as condições climáticas. Em relação ao desenho geométrico do objeto de inspeção, o estudo de Ruiz et al. (2020) que tinha como barreiras características físicas da edificação (edifício residencial de 48 metros), obstáculo de pontos de decolagem e pouso limitado, também conseguiram driblar os empecilhos através de um plano de voo, a escolha de dois pontos de decolagem-pouso e uma área destinada a pouso emergencial - Andar 1, estacionamento. A necessidade de maior cobertura de imagens pode ser solucionada através de um protocolo de procedimento experimental já existentes em estudos similares, como o de Melo, Irizarry e Costa (2016), reconhecidos na academia por suas diretrizes de voo e de captura de foto, no qual auxilia ao melhor uso do drone para coletar imagens com alta resolução, com sugestão de pontos suficientes para a sobreposição de imagens. E por fỉm, privacidade do usuário e área urbana densamente habitada com fluxo veicular, que pode ser solucionado a partir de planejamento, conforme o estudo de Ruiz et al. (2020). Esse planejamento inclui a seleção adequada de horário para moradores, evitando a invasão de privacidade para a captura de imagens e escolha de horário de menor fluxo veicular. Conclui-se, portanto, que as barreiras apresentadas pelos autores se bem planejadas e estudadas previamente podem ser resolvidas colaborando para uma inspeção eficaz.

\section{CONCLUSÕES}

No BLOCO 1, os estudos revelam que nos anais do CBPAT entre os anos de 2018 a 2020 o setor acadêmico tem investido em pesquisas para compreensão e inserção de tecnologias alternativas, especialmente os drones, para auxiliar nos desafios das inspeções voltadas para estudos em manifestações patológicas em estruturas, destacando estudos em fachadas. Ademais, pode-se observar que os drones do modelo Phantom tem se destacado nas pesquisas acadêmicas por sua confiabilidade e precisão nos resultados, além da acessibilidade de custo.

No BLOCO 2, os resultados evidenciam o maior interesse de pesquisas no CBPAT por fachadas, como dito anteriormente, e visam identificar os danos patológicos visíveis e ocultos. Além disso, nota-se que existem uma carência na padronização relacionados ao planejamento de voo e protocolo de captura de imagens e processamento de dados.

Por fim, no BLOCO 3, os dados revelam que a utilização de drone trouxe uma ampla possibilidade de benefícios na inspeção atendendo aos interesses de funcionalidade, segurança, economia e possibilitam a identificação de manifestações patológicas. E embora existam entraves na sua utilização, as pesquisas inferidas aqui, demonstram que as limitações, se bem planejadas e estudadas previamente podem ser solucionadas. No entanto, a norma de inspeção ABNT NBR 16747, publicada no ano de 2020, ainda não incluiu o drone como ferramenta legal de inspeção, 
visto que pesquisas que proporcionem dados suficientes para a definição de diretrizes de uso ainda não estão disponíveis. Por outro lado, o setor da construção civil já tem incorporado esta tecnologia como ferramenta para a realização de inspeções prediais, principalmente após alguns municípios sancionarem leis de inspeção predial abrindo um campo de trabalho vasto. Com o avanço de pesquisas com o uso de drones, a academia pode contribuir com o estabelecimento de métodos adequados, inclusive com revisão nos próximos anos da norma de inspeção, de forma a incorporar o drone como ferramenta legal para diretrizes e procedimentos de inspeção.

Diante disso, conclui-se que o setor acadêmico, especialmente a área de patologia das construções, tem mostrado grande interesse na utilização de drones para auxílio de inspeções rotineiras em estruturas. Porém, faz-se necessário a consolidação para padrões relacionados aos procedimentos metodológicos que visam melhorar a qualidade dos dados para o diagnóstico das anomalias, e assim, ampliar os benefícios dos drones na indústria da construção civil. Compreendese que este estudo trará uma percepção das lacunas existentes no que tange metodologias de inspeções, contribuindo para solucionar futuras pesquisas.

\section{AGRADECIMENTOS}

Os autores agradecem a FAPESB e CNPq pelo financiamento da pesquisa.

\section{REFERÊNCIAS}

Álvares J. S. (2016). “Mapeamento 3d de canteiros via imagens coletadas com veículo aéreo não tripulado (VANT)”. Monografia (Graduação) - Escola Politécnica, Universidade Federal de Bahia, Salvador, p. 156.

Agência Sistema FIEP. "No Brasil, 40\% dos acidentes de trabalho estão relacionados a quedas de funcionários em altura”. Disponível em: $<$ https://cutt.ly/HbYtjEy>. Acesso em: 07 de maio de 2021.

Agostinho, S. L. (2012). “Inspeção e monitorização de estruturas em engenharia civil: Utilização de UAV na inspeção e monitorização”. Dissertação (Mestrado) - Universidade da Madeira, Portugal.

Associação Brasileira de Normas Técnicas. (2013). NBR 15575 - Partes 1-6: Desempenho de Edificios Habitacionais. Rio de Janeiro.

Associação Brasileira de Normas Técnicas. (2020). NBR 16747: Inspeção predial-Diretrizes, conceitos, terminologia e procedimento. Rio de Janeiro.

Bardin, L. (1977). “Análise de conteúdo”. Edições 70, Lisboa, p. 225.

Costa, M. S. (2014). Identificação de danos em fachadas de edificações por meio de imagens panorâmicas geradas por plataforma robótica fotográfica. Dissertação (Mestrado) - Universidade de Brasília, Brasília, p. 208.

Eschmann, C. et al. (2012). "Unmanned aircraft systems for remote building inspection and monitoring”. In: Proceedings of the 6th European Workshop on Structural Health Monitoring, Dresden, Germany, p. 13. 
Hung, M. N. W. B. et al. (2018). Levantamento com veículo aéreo não tripulado para geração de modelo digital do terreno em bacia experimental com vegetação florestal esparsa. Revista Ra'e Ga Espaço Geográfico em Análise, Curitiba, v. 43, pp. 215-231.

Irizarry, J.; Costa, D. B. (2016). Exploratory Study of Potential Applications of Unmanned Aerial Systems for Construction Management Tasks. Journal of Management in Engineering. Atlanta, v. $32(3)$.

Lima, M. B. et al. (2020). Inspeção de manifestações patológicas de fachadas em edifício de grande altura com VANT. Mix Sustentável, v. 6, n. 2, pp. 111-122.

Melo Júnior, C.M. (2016). "Metodologia Para Geração de Mapas de Danos de Fachadas a Partir de Fotografias Obtidas por Veículo Aéreo não Tripulado e Processamento Digital de Imagens”. Universidade de Brasília, faculdade de tecnologia, Departamento de Engenharia Civil Ambiental. Brasília.

Melo Júnior, C. M. et al. (2018). Geração de mapas de danos de fachadas de edifícios por processamento digital de imagens capturadas por VANT e uso de fotogrametria digital. Ambiente Construído, v. 18, n. 3, pp. 211-226.

Melo, R. R. S.; Costa, D. B. (2015). "Uso de veículo aéreo não tripulado (VANT) para inspeção de logística em canteiros de obra”. In: SIBRAGEC-ELAGEC, 1., São Carlos.

Neto, M. S. (2015). “Análise cronológica do mercado dos drones no Brasil e as tendências futuras”. Disponível em: <https://cutt.ly/Xb6uV2f> Acesso em: 20 de maio de 2021.

De Moura Junior, J. M. et al. (2020). "Estudo exploratório de inspeção de manifestações patológicas de fachadas utilizando veículo aéreo não tripulado (VANT) ”. In: Congresso Brasileiro de Patologia das Construções, p. 243.

Rauber, E.R et al. (2018). Análise bibliográfica sobre as potencialidades da aquisição de imagens multi e hiperespectrais por VANTs no auxílio à inspeção de obras de arte especiais. Revista Brasileira de Geomática, Curitiba, v. 6, n. 1, pp.44-61.

Ruiz, R. D. B. et al. (2020). "Inovação na inspeção de fachadas com veículos aéreos não tripulados (VANT) ”. In: Congresso Brasileiro de Patologia das Construções, p. 650.

Sollero, M. B. S.; Santos, R.S (2020). "Uma revisão das últimas inovações em inspeções de estruturas”. In: IV Congresso Brasileiro de Patologia das Construções, pp. 2397- 2406

Tondelo, P. G; Barth, F. (2019). Análise das manifestações patológicas em fachadas por meio de inspeção com VANT. PARC - Pesquisa em Arquitetura e Construção, Campinas, SP, v. 10. 